\title{
Effects of a Food Ingredient Group on Oxidative Stress in Lead-Poisoned Mice
}

\author{
Yu-Xiu Shang a, b Yi Zhao ${ }^{b}$ Hong-Yan Qiu ${ }^{b}$ Jing-Jing Chang ${ }^{b}$ \\ Yu-Zhu Chen ${ }^{b}$ Hui-Ying Zhang ${ }^{b}$ \\ a Department of Epidemiology and Biostatistics, School of Medicine, Xi'an Jiaotong \\ University, Xi'an, and ' ${ }^{b}$ Department of Public Health, Ningxia Medical University, \\ Yinchuan, China
}

Key Words

Food ingredients · Lead-poisoned mice · Oxidative stress

\section{Abstract}

Objective: According to the principle of compatibility of traditional Chinese medicine, a food ingredient group was used to treat lead poisoning of mice. Methods: Ninety Kun-Ming male mice (18-20 g) were randomly divided into the following 6 groups: negative control group (NCG); lead acetate model group (LAG); positive drug group (PDG), and test substance groups with low-, medium-, and high-dose food ingredient group (LDG, MDG, and HDG). The test substance groups were fed with oral gavages containing the food ingredient group. The PDG were fed with gavages containing dimercaptosuccinic acid solution. The LAG and NCG were fed with gavages with deionised water. Results: One month later, both the medium and the high dose of the ingredient group had effectively increased the superoxide dismutase and glutathione peroxidase activity and decreased the malondialdehyde content in the blood, liver, kidney, and brain of the tested mice $(p<0.05)$. Compared to the PDG, we found that the MDG and HDG recovery from the lead-induced oxidative stress might be attributed to the induction of antioxidant enzyme sensitivity by the dietary supplement. Conclusion: Our findings provide evidence that the proposed food ingredient group has significant impacts on recovering from oxidative damage in lead-poisoned mice. 


\section{Introduction}

Lead is a highly toxic metal. It is one of the major pollutants to the environment and may represent a serious health hazard to humans and animals. Lead accumulation depends on its exposure duration and concentration. It reacts with a series of functional groups (e.g., sulfhydryl) in proteins, enzymes and amino acids in the body, interfering with many physiological and biochemical activities [1]. Research shows that lead can change the anti-oxidative activities of some enzymes such as superoxide dismutase (SOD) and glutathione peroxidase (GSH-PX) by suppressing the sulfhydryl. Malondialdehyde (MDA), SOD and GSH-PX might be the targets of lead toxicity $[2,3]$.

Lead poisoning causes damages to major organ systems. The kidney, blood, liver and brain are the major sites of lead accumulation and damages [4]. Research has shown that a blood lead concentration of $>0.48 \mu \mathrm{mol} / \mathrm{l}$ can cause an irreversible change of the nervous system in Chinese children [5]. An inverse correlation has been shown between children's intelligence quotient and the blood lead level. Children's cognitive ability was declined by inducing low-level exposure to lead [7]. At present, in China, the lead poisoning rate is $23.5 \%$, and the average concentration of blood lead in children was $76.5 \mu \mathrm{g} / \mathrm{l}$ over a 5-year study period [8]. Based on these results, we can conclude that lead poisoning is still at a relatively high level.

In the treatment of lead poisoning, chelating agents with the sulfhydryl group were used. However, they have side effects since they cannot only cause damages to the kidneys but they can also cause the absence of other essential elements and the metabolic disorder of antioxidant. It is necessary to develop a lead-excreting food that has fewer side effects to replace the standard lead excretion drugs. Research has shown a potential for Lycium barbarum polysaccharide (LBP) and Glycyrrhiza uralensis Fisch extract to significantly affect the antioxidant enzymes SOD and GSH-PX $[9,10]$. Numerous studies have shown that increased mung bean and jujube supply may reduce the oxidative damages of the liver $[11,12]$. The effective lead excretion components were firstly synthesized using the food ingredient group from $L$. barbarum, G. uralensis Fisch, mung bean, and jujube based on the compatibility principle of traditional medicine, i.e. the food ingredient group can decline lead accumulation and toxicity while they follow Chinese herbs. However, the impact of the food ingredient group on the oxidative damages of major organ systems in experimental animals was not reported in our country. The present study was designed to evaluate the impact of food ingredient group on the antioxidant system as well as the protective role of the food ingredient group.

\section{Materials and Methods}

Test Substance

The test substance was a powder mixture of mung bean, L. barbarum, jujube, and G. uralensis Fisch at a ratio of 8:6.25:7.5:2.5 [13]. It was prepared as an oral suspension in doses of 5, 10, and 20 times of $0.60 \mathrm{~g} / \mathrm{kg}$ body weight/day, as recommended for humans. The suspension was fed to the lead-administrated mice with an oral gavage. The mung bean powder was obtained from Heilongjiang Kangpaier Food Company, the $L$. barbarum powder from Ningxia Beirui Bio-Food Company, the jujube powder from Hebei Cangzhou Century Food Company, and the G. uralensis Fisch powder from Fujian Zhangzhou Damin Food Company.

Animal Treatment

Ninety male clean-grade Kunming mice (body weight 18-20 g) were provided by the Laboratory Animal Centre, Ningxia Medical University [quality certificate No. SCXK (Ning) 2005-0001; animal room certificate No. SYXK (Ning) 2005-0001]. The mice were treated at a temperature of $22-25^{\circ} \mathrm{C}$ and a humidity of $45-55 \%$. This study was performed in strict accordance with the recommendations in the Guide for the Care and Use of Laboratory Animals of the National Institutes of Health. The protocol was approved by the Committee on 
the Ethics of Animal Experiments of Ningxia Medical University. Surgery was performed under sodium pentobarbital anesthesia, and every effort was made to minimize suffering.

The mice could freely eat pellets and drink water and were fed and observed for 1 week. Then, they were randomly divided into the following 6 groups of 15 mice each and received i.p. feeds as follows: negative control group (NCG): $12.50 \mu \mathrm{l} / \mathrm{l}$ acetic acid deionised water during 30 days; lead acetate model group (LAG); positive drug group (PDG); low-dose group (LDG); medium-dose group (MDG), and high-dose group (HDG). The LAG, PDG, and test substance group (TSG; included LDG, MDG, and HDG) were fed with lead acetate solution (3.00 g lead acetate trihydrate dissolved in 3,000 ml deionised water; equivalent to $\mathrm{Pb}^{2+} 546.20$ $\mathrm{mg} / \mathrm{l}$ ) during 30 days. We added $12.5 \mu \mathrm{l} / \mathrm{l}$ acetic acid to acidify the solution to prevent the lead salt and the lead hydroxide from cohering [14].

After 30 days, TSG (LDG, MDG, and HDG) were fed with oral gavages containing the food ingredient group in doses of 3,6 , and $12 \mathrm{~g} / \mathrm{kg}$ body weight/day, respectively, during 30 days, which is equivalent to 5 , 10 , and 20 times the dose of $0.60 \mathrm{~g} / \mathrm{kg}$ body weight/day recommended for humans. For the PDG, the dimercaptosuccinic acid capsules were used. Based on the oral dose for a human adult, $1.5 \mathrm{~g} / 60 \mathrm{~kg}$ body weight/ day, we fed the mice a dose of $0.5 \mathrm{mg} / 20 \mathrm{~g}$ body weight/day. The drug usage and doses were the same as in clinical use for humans and the drug was given for 3 days and then stopped for 4 days. For the NCG and LAG, the deionised water was fed with an oral gavage. As the weight increased, an extra feed was added every week. Except for the PDG, all groups were fed once a day for 30 days.

Chemicals

We used the SOD detection kit, GSH-PX detection kit, and MDA detection kit (all from Nanjing Jiancheng Bioengineering Institute, China). All reagents and chemicals were of analytical grade or higher purity. The deionised water was obtained from the water purification Milli-Q system (Millipor Corporation, USA).

Outcome Measurement

At the end of experimentation, animals were sacrificed by decapitation under anesthesia. The fresh blood was immediately collected in an anticoagulation tube. The liver, kidney, and brain were picked up, washed with saline and homogenized separately. Then the concentrations of SOD, GSH-PX and MDA in the blood, liver, kidney, and brain were measured.

\section{Statistical Analysis}

The data are presented as means \pm SEM. The single-factor analysis of variance approach was applied to the experiment data, and the least significant difference method was used to compare all group pairs. Statistical significance was defined as a two-tailed $\mathrm{p}<0.05$. All statistical analyses were performed using SPSS 11.5 for Windows.

\section{Results}

Impact of the Lead Removal Product on the SOD, GSH-PX, and MDA Content in the Blood

Compared to the LAG, all the TSG showed significantly higher SOD levels ( $\mathrm{p}<0.05)$, and the MDG and HDG demonstrated significantly higher GSH-PX levels ( $p<0.05)$ and significantly lower MDA levels ( $\mathrm{p}<0.05$ ). Compared to the PDG, all the TSG displayed no statistical differences in SOD level measurements ( $p>0.05$ ), both the MDG and HDG showed significantly higher GSH-PX levels ( $p<0.05)$, and the HDG showed significantly lower MDA levels $(\mathrm{p}<0.05)$ (table 1$)$.

Impact of the Lead Removal Product on the SOD, GSH-PX, and MDA Contents in the Liver

Compared to the LAG, the MDG and HDG showed significantly higher SOD levels $(\mathrm{p}<0.05)$ and significantly lower MDA levels ( $<<0.05)$, and all the TSG demonstrated significantly higher GSH-PX levels ( $p<0.05$ ). Compared to the PDG, the MDG and HDG demonstrated significantly higher SOD levels ( $<<0.05)$, the MDG showed significantly higher GSH-PX levels $(\mathrm{p}<0.05)$, and all the TSG displayed no statistical differences in MDA levels ( $>0.05)$ (table 2). 
Integrative

Medicine

Table 1. SOD, GSH-PX, and MDA contents in the blood

\begin{tabular}{l|l}
\hline Integr Med Int 2015;2:49-55 \\
\hline DOI: 10.1159/000433469 & $\begin{array}{l}\text { @ 2015 S. Karger AG, Basel } \\
\text { www.karger.com/imi }\end{array}$ \\
\hline
\end{tabular}

Shang et al.: Effects of a Food Ingredient Group on Oxidative Stress in Lead-Poisoned Mice

\begin{tabular}{lllc}
\hline Group & SOD & GSH-PX & MDA \\
\hline NCG & $281.50 \pm 21.46$ & $79.17 \pm 10.02$ & $7.75 \pm 1.22$ \\
HDG & $253.93 \pm 19.17^{\mathrm{a}, \mathrm{b}}$ & $64.75 \pm 11.96^{\mathrm{a}-\mathrm{c}}$ & $7.87 \pm 1.27^{\mathrm{b}, \mathrm{c}}$ \\
MDG & $252.51 \pm 14.48^{\mathrm{a}, \mathrm{b}}$ & $76.68 \pm 7.72^{\mathrm{b}, \mathrm{c}}$ & $8.81 \pm 2.48^{\mathrm{b}}$ \\
LDG & $238.98 \pm 18.01^{\mathrm{a}, \mathrm{b}}$ & $30.88 \pm 9.63^{\mathrm{a}}$ & $9.53 \pm 1.79^{\mathrm{a}}$ \\
PDG & $238.15 \pm 14.86^{\mathrm{a}, \mathrm{b}}$ & $30.11 \pm 8.51^{\mathrm{a}}$ & $10.22 \pm 2.13^{\mathrm{a}}$ \\
LAG & $222.09 \pm 16.59^{\mathrm{a}}$ & $29.35 \pm 5.03^{\mathrm{a}}$ & $10.40 \pm 1.20^{\mathrm{a}}$ \\
\hline
\end{tabular}

The mean \pm SEM from 15 animals are shown in each group.

${ }^{\mathrm{a}} \mathrm{p}<0.05$ versus NCG; ${ }^{\mathrm{b}} \mathrm{p}<0.05$ versus $\mathrm{LAG}^{\mathrm{c}}{ }^{\mathrm{c}} \mathrm{p}<0.05$ versus PDG.

\begin{tabular}{llll}
\hline Group & SOD & GSH-PX & MDA \\
\hline NCG & $282.91 \pm 14.50$ & $30.20 \pm 4.31$ & $31.75 \pm 9.37$ \\
HDG & $273.53 \pm 18.41^{\mathrm{b}, \mathrm{c}}$ & $27.64 \pm 3.13^{\mathrm{b}}$ & $38.67 \pm 10.63^{\mathrm{b}}$ \\
MDG & $270.30 \pm 14.81^{\mathrm{b}}$ & $30.05 \pm 1.69^{\mathrm{b}, \mathrm{c}}$ & $37.96 \pm 4.41^{\mathrm{b}}$ \\
LDG & $257.23 \pm 14.19^{\mathrm{a}}$ & $25.82 \pm 3.33^{\mathrm{a}, \mathrm{b}}$ & $40.60 \pm 10.53^{\mathrm{a}}$ \\
PDG & $256.94 \pm 22.83^{\mathrm{a}}$ & $25.73 \pm 2.41^{\mathrm{a}, \mathrm{b}}$ & $41.15 \pm 8.34^{\mathrm{a}}$ \\
LAG & $242.66 \pm 19.06^{\mathrm{a}}$ & $22.20 \pm 3.14^{\mathrm{a}}$ & $47.88 \pm 8.46^{\mathrm{a}}$ \\
\hline
\end{tabular}

The mean \pm SEM from 15 animals are shown in each group.

${ }^{a} \mathrm{p}<0.05$ versus NCG; ${ }^{b} \mathrm{p}<0.05$ versus $L A G ;{ }^{c} \mathrm{p}<0.05$ versus PDG.
Table 2. SOD, GSH-PX, and MDA contents in the liver 
Table 3. SOD, GSH-PX, and MDA contents in the kidney

\begin{tabular}{llll}
\hline Group & SOD & GSH-PX & MDA \\
\hline NCG & $117.88 \pm 4.50$ & $4.71 \pm 0.33$ & $30.84 \pm 14.44$ \\
HDG & $111.44 \pm 6.15^{\mathrm{a}-\mathrm{c}}$ & $4.38 \pm 0.40^{\mathrm{b}, \mathrm{c}}$ & $38.24 \pm 12.70^{\mathrm{b}, \mathrm{c}}$ \\
MDG & $110.92 \pm 6.64^{\mathrm{a}-\mathrm{c}}$ & $4.25 \pm 0.57^{\mathrm{b}}$ & $42.70 \pm 13.86^{\mathrm{b}, \mathrm{c}}$ \\
LDG & $104.31 \pm 6.63^{\mathrm{a}}$ & $3.86 \pm 0.92^{\mathrm{a}}$ & $72.46 \pm 16.88^{\mathrm{a}}$ \\
PDG & $104.29 \pm 7.17^{\mathrm{a}}$ & $3.79 \pm 0.43^{\mathrm{a}}$ & $72.07 \pm 8.55^{\mathrm{a}}$ \\
LAG & $98.91 \pm 5.29^{\mathrm{a}}$ & $3.45 \pm 0.53^{\mathrm{a}}$ & $80.99 \pm 15.64^{\mathrm{a}}$ \\
\hline
\end{tabular}

The mean \pm SEM from 15 animals are shown in each group.

${ }^{\mathrm{a}} \mathrm{p}<0.05$ versus NCG; ${ }^{\mathrm{b}} \mathrm{p}<0.05$ versus $L A G ;{ }^{\mathrm{c}} \mathrm{p}<0.05$ versus PDG.
Table 4. SOD, GSH-PX, and MDA contents in the brain

\begin{tabular}{llll}
\hline Group & SOD & GSH-PX & MDA \\
\hline NCG & $169.39 \pm 36.96$ & $38.76 \pm 8.08$ & $175.33 \pm 45.47$ \\
HDG & $151.11 \pm 21.39^{\mathrm{b}}$ & $33.52 \pm 6.82^{\mathrm{b}, \mathrm{c}}$ & $222.98 \pm 38.04^{\mathrm{a}, \mathrm{b}}$ \\
MDG & $152.05 \pm 20.06^{\mathrm{b}}$ & $31.02 \pm 9.12^{\mathrm{b}, \mathrm{c}}$ & $230.61 \pm 22.78^{\mathrm{a}, \mathrm{b}}$ \\
LDG & $140.18 \pm 25.40^{\mathrm{a}, \mathrm{b}}$ & $21.09 \pm 9.83^{\mathrm{a}}$ & $246.55 \pm 28.42^{\mathrm{a}, \mathrm{b}}$ \\
PDG & $134.18 \pm 28.05^{\mathrm{a}}$ & $14.35 \pm 2.91^{\mathrm{a}}$ & $250.07 \pm 32.44^{\mathrm{a}, \mathrm{b}}$ \\
LAG & $113.71 \pm 14.69^{\mathrm{a}}$ & $12.51 \pm 1.06^{\mathrm{a}}$ & $355.91 \pm 30.42^{\mathrm{a}}$ \\
\hline
\end{tabular}

The mean \pm SEM from 15 animals are shown in each group.

${ }^{a} \mathrm{p}<0.05$ versus NCG; ${ }^{b} \mathrm{p}<0.05$ versus $L A G ;{ }^{c} \mathrm{p}<0.05$ versus PDG.

oxygen free radical scavenging capacity values slightly; GSH reductase, catalase, and SOD activity was inhibited. Lead damaged the antioxidant system in the mouse liver especially in the group exposed to high-dose lead [18]. Research has also shown that the mechanism of oxidative damage may be associated with nitric oxide (NO) metabolism. Lead showed neurotoxicity through the influence of NO and NO synthase. Lead inhibited NO synthase activity, and the degree of inhibition depends on the time and concentration of lead exposure $[19,20]$.

Research shows that (1) the mung bean contains a water-soluble pigment component, which has certain antioxidant activity, and its oxygen free radical removal rate can reach up to $70-80 \%$. The extracts of the mung bean contain protein, peptide, tannic acid, and flavonoids [21]. (2) LBP has antimutation and antioxidant effects. Providing a group exposed to lead acetate with different doses of LBP, it was found that the viabilities of SOD and GSH-PX increased with the increase of the LBP dose. The hippocampus is a part of the brain system that is responsible for studying and the spatial memory. LBP can also improve the memory of lead-administrated mice $[22,23]$. (3) Jujube polysaccharide has the effects of scavenging $\mathrm{O}^{2-}$ and $\mathrm{OH}$-. In the laboratory environment, its best scavenging rates are 19.34 and $47.30 \%$, respectively [24]. (4) G. uralensis Fisch has an antimutation effect. For example, it can suppress the sperm abnormality of mice caused by exposure to lead acetate. The extraction of $G$. uralensis Fisch has the antioxidant effect of removing the free radicals [25, 26]. In our research (preorthogonal experiments and lead excretion experiments), we found that the food ingredient group showed significant effects for lead excretion. We also found that L. barbarum and G. uralensis Fisch play a major role in excreting lead [27]. In this study, the food ingredient group was designated following the combination principles of traditional Chinese medicine and by synthesizing the effective lead excretion components in the medicinal and edible products of the mung bean, L. barbarum, jujube, and G. uralensis Fisch. In our study, both the medium and the high dose of the food ingredient group effectively increased the SOD and 
GSH-PX activity and decreased the MDA content in the blood, liver, kidney, and brain of the tested mice. We also showed that with the medium dose of the test substance, i.e. $6 \mathrm{~g} / \mathrm{kg}$ body weight/day, SOD and GSH-PX levels were significantly increased and the MDA content in the blood was significantly decreased. Compared to the PDG, we found that the HDG and MDG, as treatment of lead excretion, should have been induced antioxidant enzyme sensitivity. Therefore, the food ingredient group in our study had a better effect on antioxidant, reducing the organ damage caused by the lead poisoning and providing certain treatments.

In our study, the food ingredient group (test substance) was medicinal and edible food (a kind of natural food). Many studies have confirmed that medicinal and edible foods could prevent and treat disease with fewer side effects. In accordance with the principle of formulating a prescription and by analyzing the nature and flavor of food and medicine, we designed the formula mainly with a sweetish taste. With a combination of two herbs of neutral nature, one of warm nature and one of cold nature, the formula possesses a nature of mildness. From the nutritional point of view, it is high in protein and rich in trace elements, which is similar to human food, while the oxidative damage caused by lead poisoning has a therapeutic effect. As is well known, the standard lead excretion drugs, such as calcium disodium EDTA and D-penicillamine, have serious side effects and are nonspecific. These drugs do not only promote lead excretion but could also promote the excretion of certain essential metal elements. In addition, these chelating agents cause obvious toxicity for the kidney. In clinical 1-, 2-, 3-level lead poisoning in children, it was not recommended to use those drugs to drive the lead treatment. Instead, it was suggested to intake diet or supplementary nutrients to promote the body to excrete lead. In summary, the medicinal and edible food (food ingredient group) is either anti-oxidation, lead excretion, and can also supplement the lack of nutrients. The most important role of those foods is that they have fewer side effects.

Our findings provide evidence that the proposed food ingredient group has significant impacts on recovering from the oxidative damage in the lead-poisoned mice.

\section{Acknowledgments}

This study was supported by grants from Ningxia Colleges and Universities Technology Research Key Project (No. 2010-297). We thank Professor Xiu-Fang Liu for the administrative support in designing the study. We also thank Ling Wang, Peng-Ju Zhang and Xiu-Ying Liu for their assistance in the experiments.

\section{Disclosure Statement}

All authors have approved the paper and declare no competing financial interests.

\section{References}

1 Yu FJ: The Study of Cadmium and Lead Toxicity on the Chinese Mitten-Handed Crab Eriocheir sinensis. Shanghai, East China Normal University, 2005.

-2 El-Sokkary GH, Abdel-Rahman GH, Kamel ES: Melatonin protects against lead-induced hepatic and renal toxicity in male rats. Toxicology 2005;213:25-33.

-3 Nehru B, Kanwar SS: Modulation by N-acetylcysteine of lead-induced alterations in rat brain: reduced glutathione levels and morphology. Toxicol Mech Methods 2007;17:289-293.

4 Sharma R, Street J: Public health aspects of toxic heavy metals in animal feeds. J Am Vet Med Assoc 1980;177: 149-153.

5 Xiong HJ, Lei XY, Zhao YF, Yuan BS, Li R, Niu JP: A study on the relationship between blood lead level and intelligence quotient in children. Chin J Pract Pediatr 2000;15:731-732. 
-6 Rummo JH, Routh DK, Rummo NJ, Brown JF: Behavioral and neurological effects of symptomatic and asymptomatic lead exposure in children. Arch Environ Health 1979;34:120-124.

7 Fulton M, Raab G, Thomson G, Laxen D, Hunter R, Hepburn W: Influence of blood lead on the ability and attainment of children in Edinburgh. Lancet 1987;1:1221-1226.

8 Qing JF, Li ZX, Lou MT: Analysis and research of the rate of childhood lead poisoning in China, 2003-2007 - the result of blood lead determination. Guangdong Trace Elements Science 2009;16:15-27.

-9 Cho SH, Park EJ, Kim E0, Choi SW: Study on the hypochlolesterolemic and antioxidative effects of tyramine derivatives from the root bark of Lycium chenese Miller. Nutr Res Pract 2011;5:412-420.

10 Gumpricht E, Dahl R, Devereaux MW, Sokol RJ: Licorice compounds glycyrrhizin and 18beta-glycyrrhetinic acid are potent modulators of bile acid-induced cytotoxicity in rat hepatocytes. J Biol Chem 2005;280:1055610563.

11 Dahiru D, Obidoa 0: Evaluation of the antioxidant effects of Ziziphus mauritiana Lam. Leaf extracts against chronic ethanol-induced hepatotoxicity in rat liver. Afr J Tradit Complement Altern Med 2007;5:39-45.

$\$ 12$ Atawodi SE: Nigerian foodstuffs with prostate cancer chemopreventive polyphenols. Infect Agent Cancer 2011;6(suppl 2):S9.

13 Chen YZ, Zhang HY, Wang JY, Liu GZ, Miao Y: Ratio optimization of lead-removing products by orthogonal test. Food Drug 2009;11:43-45.

14 Liu XY, Hu YX, Qiu F, Liu FQ, Wang CE, Zang XB: Exploration of water lead exposure for mouse model and suitable for assessing lead-eliminating effect of health foods. Chin J Food Hygiene 2003;15:291-294.

15 Farant JP, Wigfield DC: Biomonitoring lead exposure with $\delta$-aminolevulinate dehydratase (ALA-D) activity ratios. Int Arch Occup Environ Health 1982;51:15-24.

16 Sandhir R, Julka D, Gill KD: Lipoperoxidative damage on lead exposure in rat brain and its implications on membrane bound enzymes. Pharmacol Toxicol 1994;74:66-71.

17 El-Sokkary GH, Kamel ES, Reiter RJ: Prophylactic effect of melatonin in rescuing lead-induced neurotoxicity in the rat. Cell Mol Biol Lett 2003;8:461-470.

$18 \mathrm{Xu} \mathrm{J}$, Xu LH, Zheng YF, Xing ML, Tang JG, Yu ZY: Antioxidant defense system damage in the liver of mouse exposed to lead. Acta Scientiae Circumstantiae 2004;24:1142-1144.

19 Zhu ZW, Yang RL, Dong GJ, Zhao ZY: Study on the neurotoxic effects of low-level lead exposure in rats. J Zhejiang Univ Sci B 2005;6:686-692.

-20 García-Arenas G, Ramírez-Amaya V, Balderas I, Sandoval J, Escobar ML, Ríos C, Bermúdez-Rattoni F: Cognitive deficits in adult rats by lead intoxication are related with regional specific inhibition of cNOS. Behav Brain Res 2004;149:49-59.

21 Marathe SA, Rajalakshmi V, Jamdar SN, Sharma A: Comparative study on antioxidant activity of different varieties of commonly consumed legumes in India. Food Chem Toxicol 2011;49:2005-2012.

22 Li SY, Yang D, Yeung CM, Yu WY, Chang RC, So KF, Wong D, Lo AC: Lycium barbarum polysaccharides reduce neuronal damage, blood-retinal barrier disruption and oxidative stress in retinal ischemia/reperfusion injury. PLoS One 2011;6:e16380.

23 Yu SL, Cai Y: The influence of Lycium barbarum polyccharides (LBP) on NO and NOS in hippocampus of leadexposed mice. Pharmacol Clin Chin Materia Medica 2006;22:41-42.

24 Li ZZ, Chen JZ: The study of anti-oxidation property in jujube polysaccharide. Sci Technol Food Ind 2007;28: 115-117.

25 Huo HZ, Wang B, Liang YK, Bao YY, Gu Y: Hepatoprotective and antioxidant effects of licorice extract against CCl4-induced oxidative damage in rats. Int J Mol Sci 2011;2:6529-6543.

-26 Kang JS, Yoon YD, Cho IJ, Han MH, Lee CW, Park SK, Kim HM: Glabridin, an isoflavan from licorice root, inhibits inducible nitric-oxide synthase expression and improves survival of mice in experimental model of septic shock. J Pharmacol Exp Ther 2005;312:1187-1194.

27 Chen YZ, Zhang HY, Wang L, Zhang PJ: Lead-eliminating effect of a lead-excreting food on lead poisoning in mice. Chin J Food Hygiene 2010;22:254-257. 